
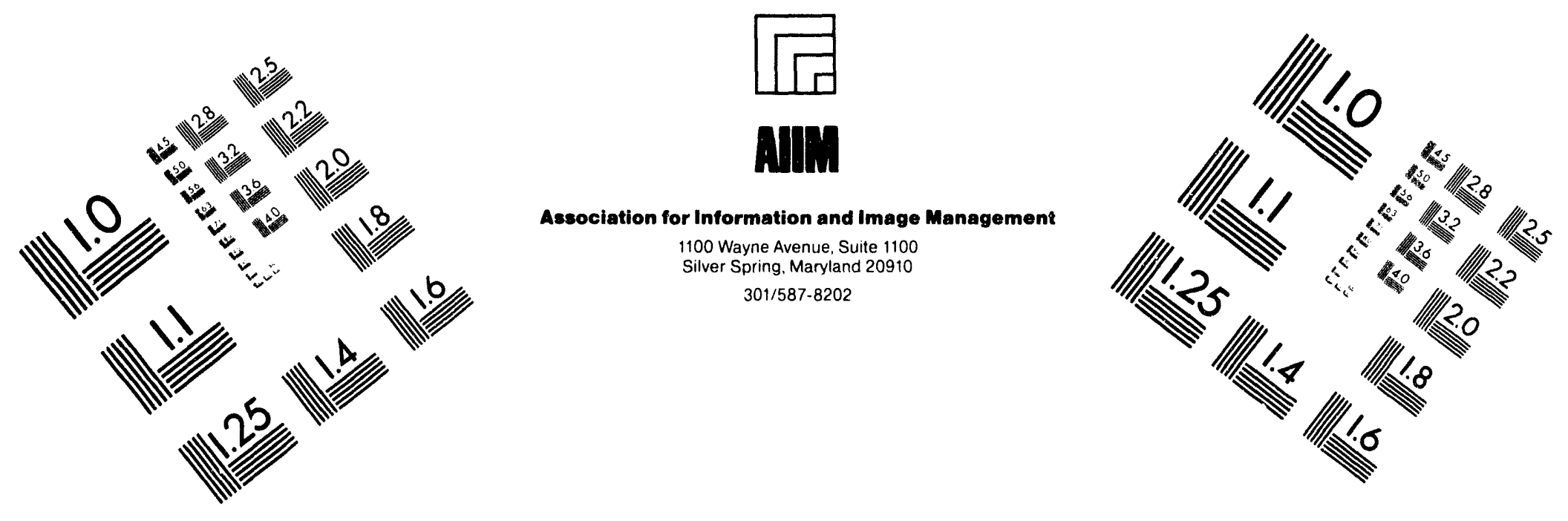

\title{
Centimeter
}

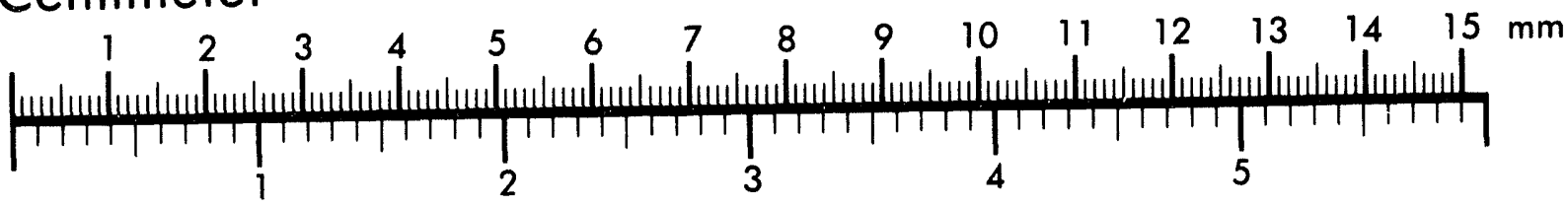

Inches
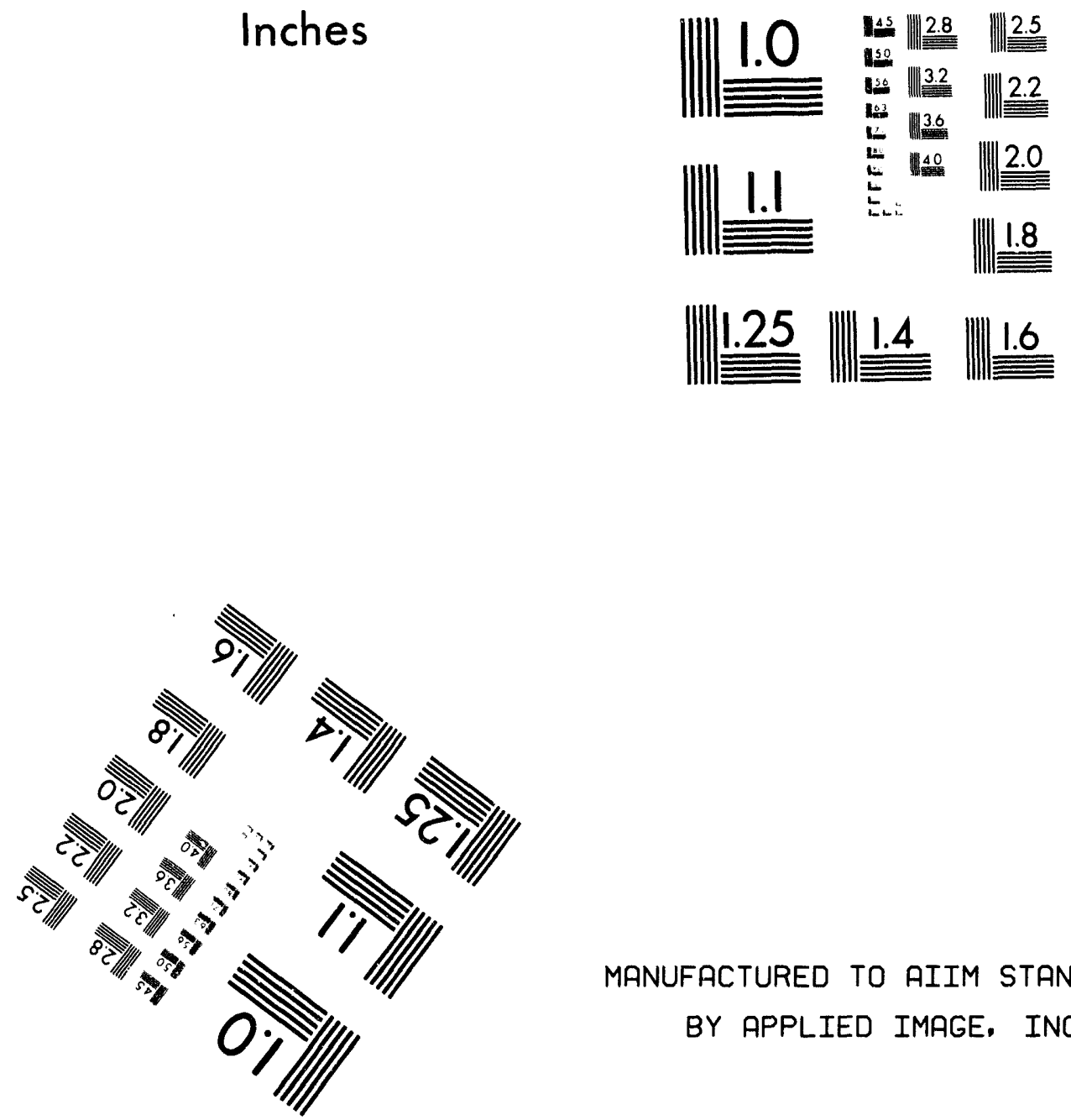

MANUFACTURED TO AIIM STANDARDS

BY APPLIED IMAGE, INC.

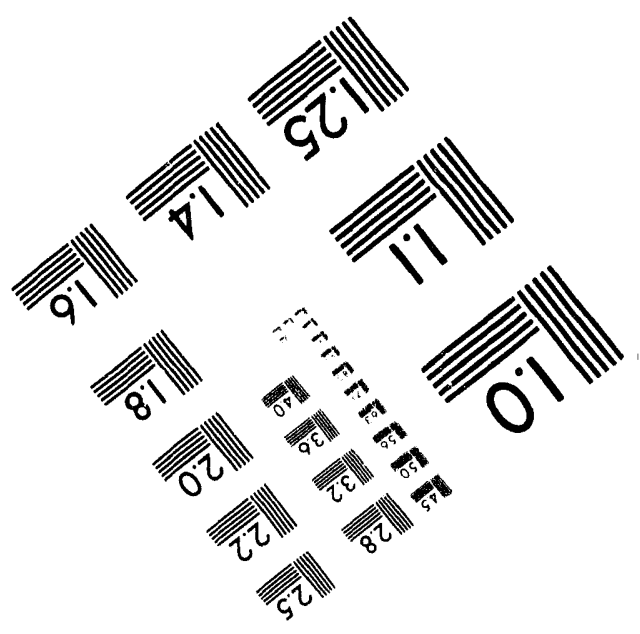



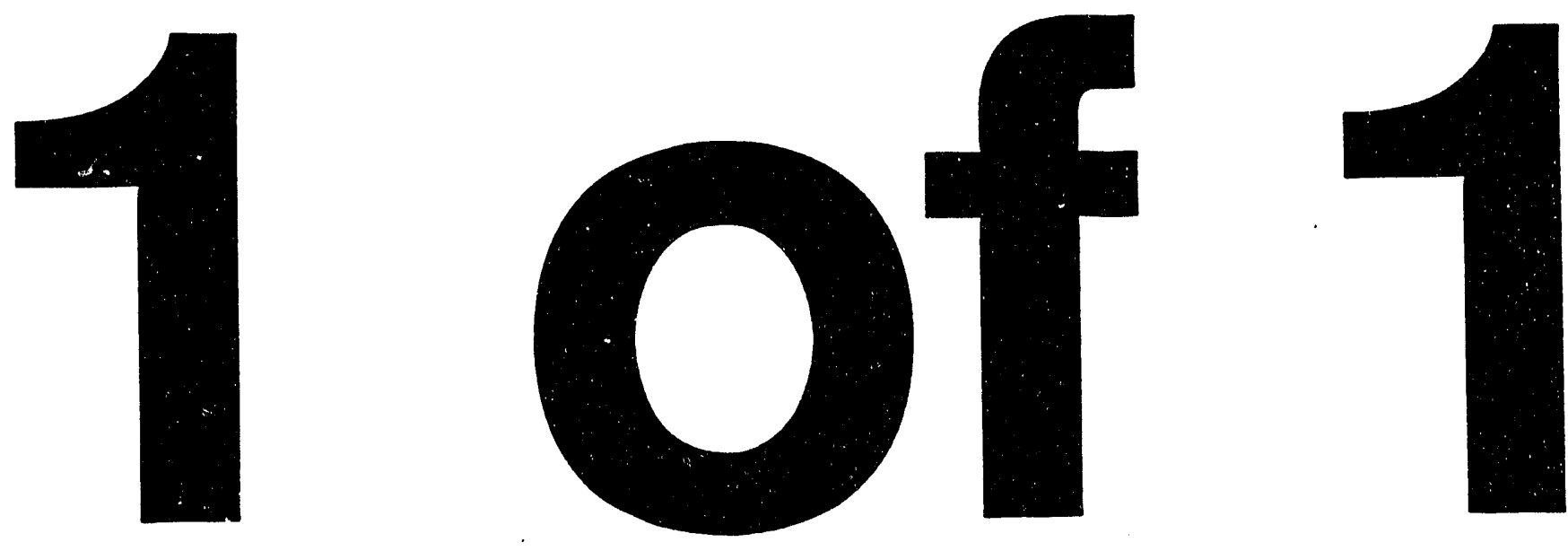
SAND 94-8704

Unlimited Release

Printed August 1994

\title{
THE MODIFIED EMBEDDED ATOM METHOD
}

\author{
M. I. Baskes \\ Materials and Process Research Department
}

\begin{abstract}
Recent modifications have been made to generalize the Embedded Aton Method (EAM) to describe bonding in diverse materials. By including angular dependence of the electron density in an empirical way, the Modified Embedded Atom Method (MEAM) has been able to reproduce the basic energetic and structural properties of 45 elements. This method is ideally suited for examining the interfacial behavior of dissimilar materials.

This paper will explain in detail the derivation of the method, show how the parameters of the MEAM are determined directly from experiment or first principles calculations, and examine the quality of the reproduction of the database.

Materials with fcc, bcc, hcp, and diamond cubic crystal structure will be discussed. A few simple examples of the application of the MEAM to surfaces and interfaces will be presented. Calculations of pullout of a $\mathrm{SiC}$ fiber in a diamond matrix as a function of applied stress show non-uniform deformation of the fiber.
\end{abstract}




\section{THE MODIFIED EMBEDDED ATOM METHOD}

\section{INTRODUCTION}

Empirical and semi-empirical computational methods for metals and covalent materials have evolved rapidly in the past few years. These methods have recently been reviewed by Carlsson (Ref. 13), in an MRS Symposium (Ref. 35), and at a special symposium of the World Materials Congress (Ref. 37). The Embedded Atom Method (EAM) has been the mainstay of the new methods used for metallic systems. Daw and Baskes (Refs. 13, 14) introduced this method over a decade ago. The EAM, which is based on density functional theory, has successfully been applied to the fcc or nearly-filled d-band transition metals and also to bcc metals (Refs. 1, 28). A number of recent papers summarize the technique and its many applications (Refs. 5, 6, 14, 15, $17,18,21,22,23$ ). Finnis and Sinclair (Ref. 20) derived a similar method based on a second moment approximation to tight binding and originally applied it to the bcc or half-filled d-band transition metals.

A basic limitation of the EAM is that it spherically averages the electron density which precludes directional bonding. Baskes (Ref. 2) modified the EAM to include directional bonding and applied it to silicon. The silicon EAM model was extended by Baskes, et al. (Ref. 8) to the silicon/germanium system where the Modified Embedded Atom Method (MEAM) was developed. Most recently the MEAM has been extended to fcc, bcc (Ref. 3) and hcp (Ref. 7) metals. Savino et al. (Ref. 34) developed a related method based on second order invariants.

All of these methods are mathematically similar and have in common the attribute that the interaction between two atoms depends upon their local environment. It is mainly this fact that accounts for the success that these methods have had in predicting effects at metallic surfaces where the atomic environment is significantly different from the bulk.

This paper will review the derivation of the MEAM and its application to a large number of elements showing its wide range of applicability. An underlying theme in the development of the methor is computational simplicity so that the interactions may be readily used for large molecular dynamics or Monte Carlo simulations. MEAM functions for the $\mathrm{Si} / \mathrm{C}$ system will be developed and applied to the deformation of a SiC fiber in a diamond matrix. 


\section{THEORY}

The total energy $\mathrm{E}$ of a system of atoms in the Embedded Atom Method (EAM) has been shown (Ref. 16) to be given by an approximation of the form:

$$
E=\sum_{i}\left(F_{i}\left(\bar{\rho}_{i}\right)+\frac{1}{2} \sum_{j \neq i} \phi_{i j}\left(R_{i j}\right)\right)
$$

where the sums are over the atoms $\mathrm{i}$ and $\mathrm{j}$. ${ }^{*}$ In this approximation, the embedding function $\mathrm{F}_{\mathrm{i}}$ is the energy to embed an atom of type $i$ into the background electron density at site $1, \bar{\rho}_{i}$; and $\phi_{i j}$ is a pair interaction between atoms $i$ and $j$ whose separation is given by $R_{j i}$. In the EAM, $\hat{\rho}_{\text {i }}$ is given by a linear supposition of spherically averaged atomic electron densities, while in the Modified Embedded Atom Method (MEAM), $\bar{\rho}_{i}$ is augmented by angularly dependent terms (Refs. 2, 3, 7, 8). Let us denote the term in brackets in Eq. 1, i.e., the direct contribution to the energy from the $\mathrm{i}$ th atom, as $\mathrm{E}_{\mathrm{i}}$. Of course, atom $\mathrm{i}$ also indirectly contributes to the energy through its interactions with its neighbors. Then $\mathrm{E}_{\mathrm{i}}$ rnay be written as follows:

$$
E_{i}=F_{i}\left(\bar{\rho}_{i}\right)+\frac{1}{2} \sum_{j \neq i} \phi_{i j}\left(R_{i j}\right)
$$

As in Baskes et al. (Refs. 3, 8) consider the case of a homogeneous monatomic solid with interactions limited to first neighbors only. In a specific reference structure (usually the equilibrium structure) for an atom of type i we have:

$$
E_{i}^{u}(R)=F_{i}\left(\bar{\rho}_{i}^{0}(R)\right)+\frac{1}{2} Z_{i} \phi_{i i}(R)
$$

where $\bar{\rho}_{i}^{0}(R)$ is the background electron density for the reference structure of atom $\mathrm{i}, \mathrm{Z}_{\mathrm{i}}$ is the coordination, and $\mathrm{R}$ is the nearest neighbor distance. Here $E_{1}^{u}(R)$ is the energy per atom of the reference structure as a function of nearest neighbor distance, obtained, e.g., from first principles calculations or the universal equation of state of Rose et al. (Ref. 32). Here we choose the latter:

$$
E_{i}^{\prime \prime}(R)=-E_{c}\left(1+\alpha\left(\frac{R}{r_{e}}-1\right)\right) e^{-\alpha\left(R / r_{e}-1\right)}
$$

with

$$
\alpha^{2}=\frac{9 \Omega B}{E_{c}}
$$

where $\mathrm{E}_{\mathrm{c}}, \mathrm{r}_{\mathrm{e}}, \Omega$, and $\mathrm{B}$ are the cohesive energy, nearest-neighbor distance, atomic volume, and bulk modulus, respectively, all evaluated at equilibrium in the reference state. The pair potential for like atoms is then given by:

$$
\phi_{i i}(R)=\frac{2}{Z_{i}}\left\{E_{i}^{\prime \prime}(R)-F_{i}\left(\bar{\rho}_{i}^{0}(R)\right)\right\} .
$$

At equilibrium $\left(\right.$ denoted by $\left.\right|_{r}$ ), with the use of this form, $\left.E\right|_{\text {re }}=-E_{\text {a }}, d E /\left.d r\right|_{r=}=0$, and $\left.d^{2} E^{\prime} d r^{2}\right|_{r e}=9 \Omega B / r_{e}^{2}$ so that agre'ement is assured between the model and the inpurt cohesive energy, atomic volume, and bulk modulus. The pair potential for unlike atom pairs will be discussed ivilow.

\footnotetext{
* Throughout the paper the subscripts $(\mathrm{i}, \mathrm{j}, \mathrm{k})$ denote either an atom at a particular site or the type of that atom.
} 
In the MEAM the embedding function $F(\rho)$ is taken as

$$
F(\rho)=A E_{c} \frac{\rho}{\rho_{0}} \ln \frac{\rho}{\rho_{0}}
$$

where $\mathrm{A}$ is an adjustable parameter and $\rho_{0}$ is a density scaling parameter. See Baskes et al. (Refs. 2,8 ) for a justification of this functional form. The density scaling parameter was initially (Ref. 3) taken to be the coordination times the atomic density scaling factor (see Eq. 11 below) and more recently (Ref. 7) as the density in the equilibrium reference structure. The SiC calculations presented below use the latter definition. For fcc and bcc reference lattices the definitions are identical. For hcp and diamond cubic there is a si i.ll difference.

The background electron density, $\bar{\rho}_{i}$, is assumed to be a function of what we call partial electron densities. These partial electron densities contain the angular information in the model. The reader should be cautioned that even though the electron density may be thought of as qualitatively similar to a real electron density, there is no expectation that the electron densities calculated here would be in agreement with those obtained from first principles calculations. A number of functional forms have been used previously (Refs. $2,3,4,7,8$ ).

For example, the square of the electron density at a given site has previously (Ref. 3) been defined as the sum of terms with $\mathrm{s}, \mathrm{p}$, $\mathrm{d}$, and $\mathrm{f}$ symmetry from the neighboring atoms. By including these angular terms in the background electron density, we introduce angular forces into the model. Thus at a particular atom:

$$
\bar{\rho}^{2}=\sum_{h=0}^{3} t^{(h)} \rho^{(h) 2}
$$

with $h=0$ to 3 corresponding to $s, p, d$, and $f$ symmetry, respectively, and for convenience we take $t(0)=1$. We note that in a crystal the $s, p, d$, and $f$ terms may be considered as measures of volume, polarization, shear, and lack of inversion symmetry, respectively. For example, as we vary the volume of a perfect fcc lattice, only $\rho(0)$ is not equal to zero and, thus, it can simply be related to the volume. Similarly as we shear the fcc lattice, contributions from $\rho(2)$ arise. An alternative exponential form with the same asymptotic behavior near the perfect lattice has also been used (Ref. 7):

$$
\bar{\rho}=\rho^{(0)} e^{\left[\frac{1}{2} \sum_{h=1}^{3} t^{(h)}\left(\rho^{(h)} / \rho^{(0)}\right)^{2}\right]} .
$$

The contributions to the density are given by:

$$
\begin{gathered}
\rho^{(0)}=\sum_{i} \rho^{a(0)}\left(r^{i}\right) \\
\left(\rho^{(1)}\right)^{2}=\sum_{\alpha}\left[\sum_{i} \rho^{a(1)}\left(r^{i}\right) \frac{r_{\alpha}^{i}}{r^{i}}\right]^{2} \\
\left(\rho^{(2)}\right)^{2}=\sum_{\alpha, \beta}\left[\sum_{i} \rho^{u(2)}\left(r^{i}\right) \frac{r_{\alpha}^{i} r_{\beta}^{i}}{r^{i 2}}\right]^{2}-\frac{1}{3}\left[\sum_{i} \rho^{a(2)}\left(r^{i}\right)\right]^{2} \\
\left(\rho^{(3)}\right)^{2}=\sum_{\alpha, \beta, \gamma}\left[\sum_{i} \rho^{a(3)}\left(r^{i}\right) \frac{r_{\alpha}^{i} r_{\beta}^{i} r_{\gamma}^{i}}{r^{i 3}}\right]^{2} .
\end{gathered}
$$

Here, the $\rho^{a(h)}$ are radial functions which represent the decrease in the contribution with distance $r^{1}$ from the site in question, the superscript $i$ indicates neighboring atoms to the site in 
question, and the $\alpha, \beta$, and $\gamma$ summations are each over the three coordinate directions with $r^{\prime}$ being the distance from the site in question in that direction. The functional forms for the partial electron densities $(h=1,3)$ were chosen to be translationally and rotationally invariant and equal to zero for crystals with cubic symmetry. Finally, the individual contributions are assumed to decrease exponentially, i.e.,

$$
\rho^{a(h)}(R)=\rho_{0}^{a} e^{-\beta^{(h)}\left(R / r_{e}-1\right)}
$$

where $\rho_{0}^{a}$ and $\beta(\mathrm{h})$ are constants. For alloys the coefficients $t(\mathrm{~h})$ were initially assumed to depend on the properties of the atom at which the average electron density was calculated (Ref. 3 ). More recently (Ref. 26) it has been found that better agreement with defect properties in SiC could be obtained if the properties of the atoms surrounding this atom were included. The latter averaging procedure is used below for the SiC calculations:

$$
t^{(h)}=\sum_{i} t_{i}^{(h)} \rho_{0}^{a(0)} / \rho^{(0)} .
$$

The determination of the parameters has been discussed previously (Refs. 3, 7) in great detail. Basically, analytic expressions are obtained for the elastic constants, vacancy formation energy, and structural energy differences. Using these expressions and experimental data each parameter (or sets of parameters) is uniquely defined. The relationship between the parameters and the experimental input is summarized in Table 1. A number of the $\beta$ parameters are not well determined for the fcc and bcc elernents and nominal values are chosen for convenience.

Table 1 - Parameters and their correspondence with experimental data.

\begin{tabular}{ll}
\hline \hline Parameter & Experimental Input \\
\hline $\mathrm{E}_{\mathrm{c}}$ & sublimation energy \\
$\mathrm{r}_{\mathrm{e}}$ & atomic volume \\
$\alpha$ & bulk modulus \\
$\mathrm{A}$ & structural energy difference \\
$\beta(0), \mathrm{t}(2)$ & shear moduli \\
$\beta(1)$ & internal relaxation for hcp \\
$\beta(2), \beta(3)$ & shear moduli for hcp \\
$\mathrm{t}(1)$ & vacancy formation energy \\
$\mathrm{t}(3)$ & stacking fault energy or c/a for hcp \\
\hline
\end{tabular}




\section{RESULTS AND DISCUSSION}

We begin this section with a diagram of the periodic table that shows the elements for which MEAM functions have been developed. These functions are now available for the 45 elements denoted by shaded squares. As you can see in Fig. 1, MEAM functions exist for most of the
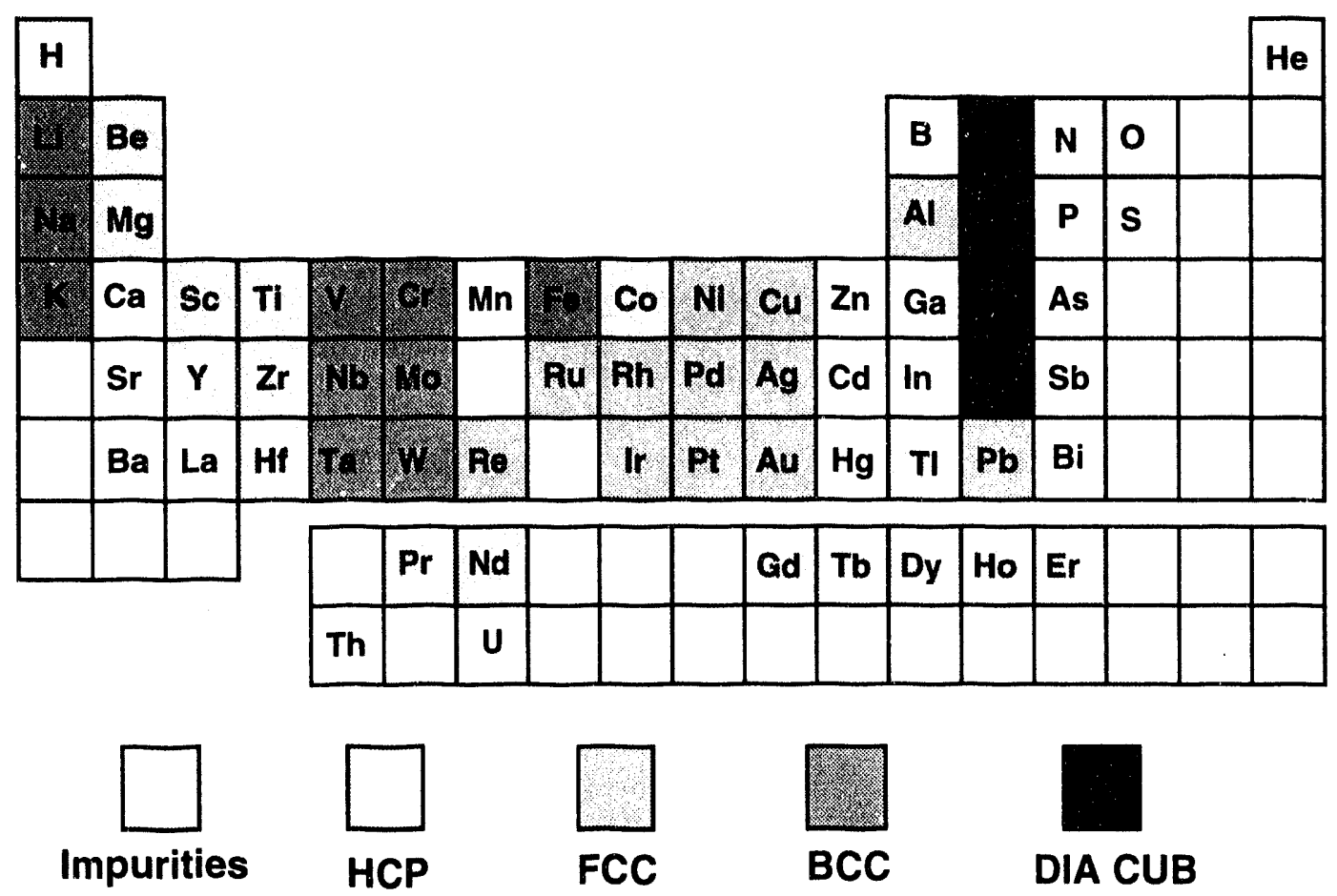

Figure 1 - Periodic table of the elements showing the current status of MEAM function development. The shaded squares denote those elements for which MEAM functions currently exist.

technologically interesting elements. We are currently in the process of developing MEAM functions for the additional elements whose names are present in unshaded squares. It should be noted that once functions are available for a pair of elements it is relatively simple to produce the pair interactions so that alloy or compound calculations may be performed. We have no current interest in the other elements in the table.

To examine the ability of the MEAM to represent the properties of "real materials" a number of examples are presented. The MEAM parameters used here are those previously presented (Refs. $3,7)$. As a first example the surface energy of a number of materials is shown in Fig. 2. Here we plot the calculated surface energy of a (100) face using MEAM vs. the experimental value of an "average" surface extrapolated to $0 \mathrm{~K}$. Also included in the "experimental" data set are calculated estimates from de Boer, et al. (Ref. 19). As the figure shows the agreement with experiment is quite good for most of the elements. In contrast, EAM calculations of surface energy (Ref. 24) are frequently in disagreement with experiment by up to $40 \%$.

As a second example calculated structural energies are shown in Fig. 3. The energies shown in the figure are those obtained after minimiz stion with respect to lattice constant. The calculations are compared to an estimate of structural energy differences derived from analyses of experimental phase diagrams (Ref. 33), stacking fault energies (Refs. 25, 29, 31) and first principles calculations (Ref. 30). 


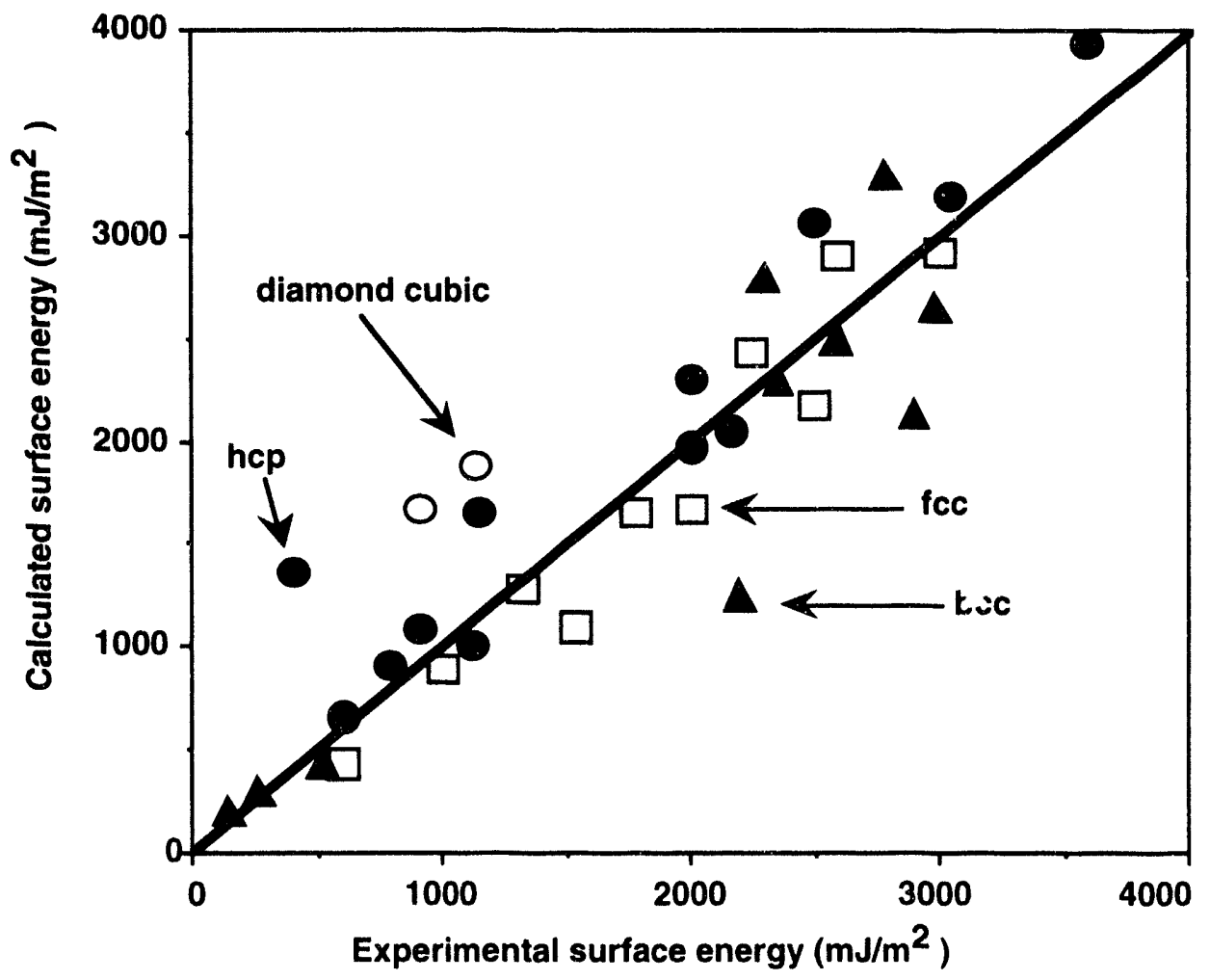

Figure 2 - Comparison of experimental (Refs. 19, 27, 36) and calculated surface energies for various elements. The elements shown are those denoted in Fig. 1. 


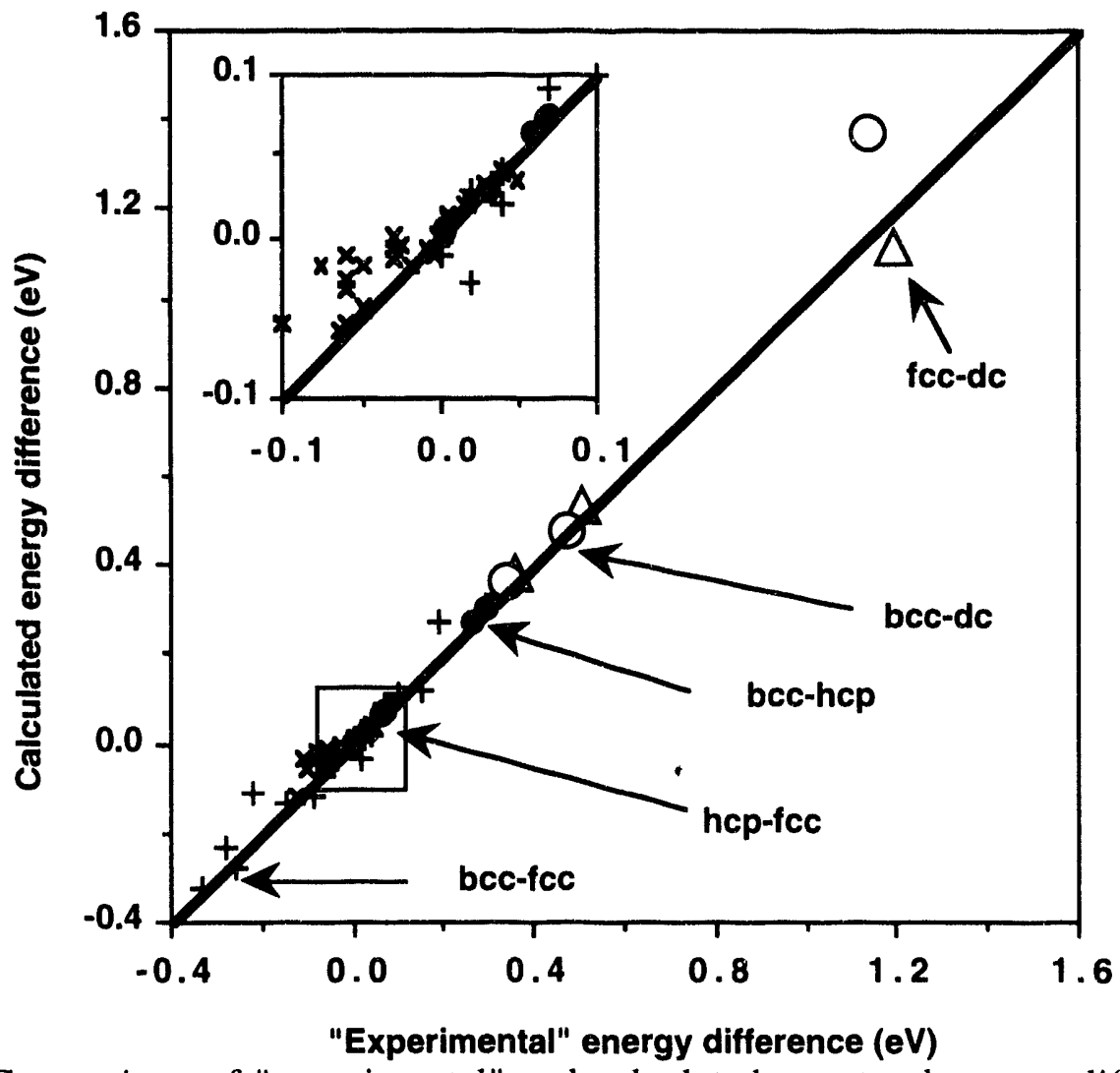

Figure 3 - Comparison of "experimental" and calculated structural energy differences for various elements. The elements shown are those denoted in Fig. 1. See text for how the "experimental" values are determined. The inset shows the detail for very small energy differences. 
The final example is that of a small $\mathrm{SiC}$ fiber embedded in a matrix of diamond. The MEAM potentials for silicon and carbon have been modified slightly from those previously developed (Ref. 3) to include use of the exponential form for the average electron density and more recent elastic constants of carbon (Ref. 38). The parameters for the new potentials are given in Table 2.

\section{Table 2 - Parameters for the MEAM}

Values listed are the cohesive energy $\mathrm{E}_{\mathrm{c}}(\mathrm{eV})$, the equilibrium nearest neighbor distance $\mathrm{r}_{\mathrm{e}}(\AA)$, the exponential decay factor for the universal energy function $\alpha$, the scaling factor for the embedding energy $A$, the exponential decay factors for the atomig densities $\beta$ (ค), the weighting factors for the atomic densities $t(\mathrm{I})$, and the density scaling factor $\rho_{0}$.

\begin{tabular}{cccccccccccccc}
\hline \hline & $\mathrm{E}_{\mathrm{c}}$ & $\mathrm{r} \mathrm{e}$ & $\alpha$ & $\mathrm{A}$ & $\beta^{(0)}$ & $\beta^{(1)}$ & $\begin{array}{c}\beta \\
(2)\end{array}$ & $\begin{array}{c}\beta \\
(3)\end{array}$ & $\mathrm{t}^{(1)}$ & $\mathrm{t}^{(2)}$ & $\mathrm{t}^{(3)}$ & $\rho_{0}^{a}$ \\
\hline $\mathrm{C}$ & 7.3 & 1.5 & 4.3 & 1.0 & 4.1 & 4.2 & 5.0 & 3.0 & 5.0 & 9.34 & -1.0 & 2.5 \\
& 7 & 4 & 8 & & & & & & & & & \\
$\mathrm{Si}$ & 4.6 & 2.3 & 4.8 & 1.0 & 4.8 & 4.8 & 4.8 & 4.8 & 3.3 & 5.11 & -0.8 & 1.0 \\
& 3 & 5 & 7 & & & & & & & & & \\
$\mathrm{SiC}$ & 6.4 & 1.8 & 4.3 & - & - & - & - & - & - & - & - & - \\
3 & 9 & 7 & & & & & & & & & \\
\hline
\end{tabular}

In Table 3 the elastic constants and vacancy formation energy calculated from these functions are compared to experiment. Agreement is excellent.

Table 3 - Elastic constants and vacancy formation energies for $\mathrm{C}$ and $\mathrm{Si}$.

The experimental elastic constants are from Refs. 10 and 38 and the first principles calculations of vacancy formation energies are from Refs. 9, 11, and 12 .

\begin{tabular}{ccrcrcccc}
\hline \hline & $\mathrm{c} 11\left(\mathrm{eV} / \AA^{3}\right)$ & \multicolumn{2}{c}{$\mathrm{c}_{12}\left(\mathrm{eV} / \AA^{3}\right)$} & $\mathrm{c} 44\left(\mathrm{eV} / \AA^{3}\right)$ & \multicolumn{2}{c}{$E_{1 v}^{f}(\mathrm{eV})$} \\
\hline & Calc. & Expt. & Calc. & Expt. & Calc. & Expt. & Calc. & Theory \\
$\mathrm{C}$ & 6.77 & 6.74 & 0.77 & 0.78 & 3.66 & 3.61 & 6.5 & 7.2 \\
$\mathrm{Si}$ & 1.01 & 1.03 & 0.41 & 0.40 & 0.46 & 0.48 & 3.0 & $5-6$ \\
\hline
\end{tabular}

The reference state for the alloy system is taken to be the diamond cubic structure $(\beta)$ of SiC. The parameters for the equation of state are given in Table 2 . Using a method similar to that described in Baskes (Ref. 3), the following expression is obtained for the Si-C pair potential:

$$
\phi_{\mathrm{SiC}}=\frac{1}{4}\left\{2 E_{\mathrm{SiC}}^{u}-F_{\mathrm{C}}\left(\bar{\rho}_{\mathrm{C}}^{0}\right)-F_{\mathrm{Si}}\left(\bar{\rho}_{\mathrm{Si}}^{0}\right)\right\}
$$

where

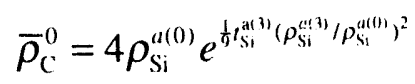

and 


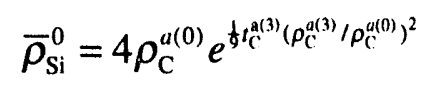

The elastic constants of $\mathrm{SiC}$ using the above potentials are calculated to be: bulk modulus 1.32 $\mathrm{eV} / \AA^{3}$; shear modulus (c44) $1 . .28 \mathrm{eV} / \AA^{3}$; and second shear modulus $0.89 \mathrm{eV} / \AA^{3}$. By construction the cohesive energy, lattice constant, and bulk modulus agree exactly with experiment.

Calculations were performed to simulate the deformation of a $\mathrm{SiC}$ fiber in a diamond carbon (C) matrix. The geometry is shown in Fig. 4. Both the $\mathrm{SiC}$ and $\mathrm{C}$ are single crystals with a (100) orientation. The computational cell is about $40 \AA$ long in the axial direction which is 11 unit cells of $\mathrm{C}$ and 9 unit cells of $\mathrm{SiC}$. Choosing this ratio of cells allows almost perfect matching of the periodicity of the $\mathrm{C}$ and $\mathrm{SiC}$. The $\mathrm{SiC}$ fiber is $10 \AA$ in diameter. The surrounding $\mathrm{C}$ matrix is effectively infinite in radial extent with $C$ atoms outside of a $20 \AA$ diameter cylinder held fixed in space. The fiber/matrix cell is allowed to relax to its minimum energy configuration. To restrict interactions to first neighbors, screening is included as in Ref. 7. Axial forces are then applied to each atom of the $\mathrm{SiC}$ fiber and the atoms are allowed to relax to their minimum energy configuration.

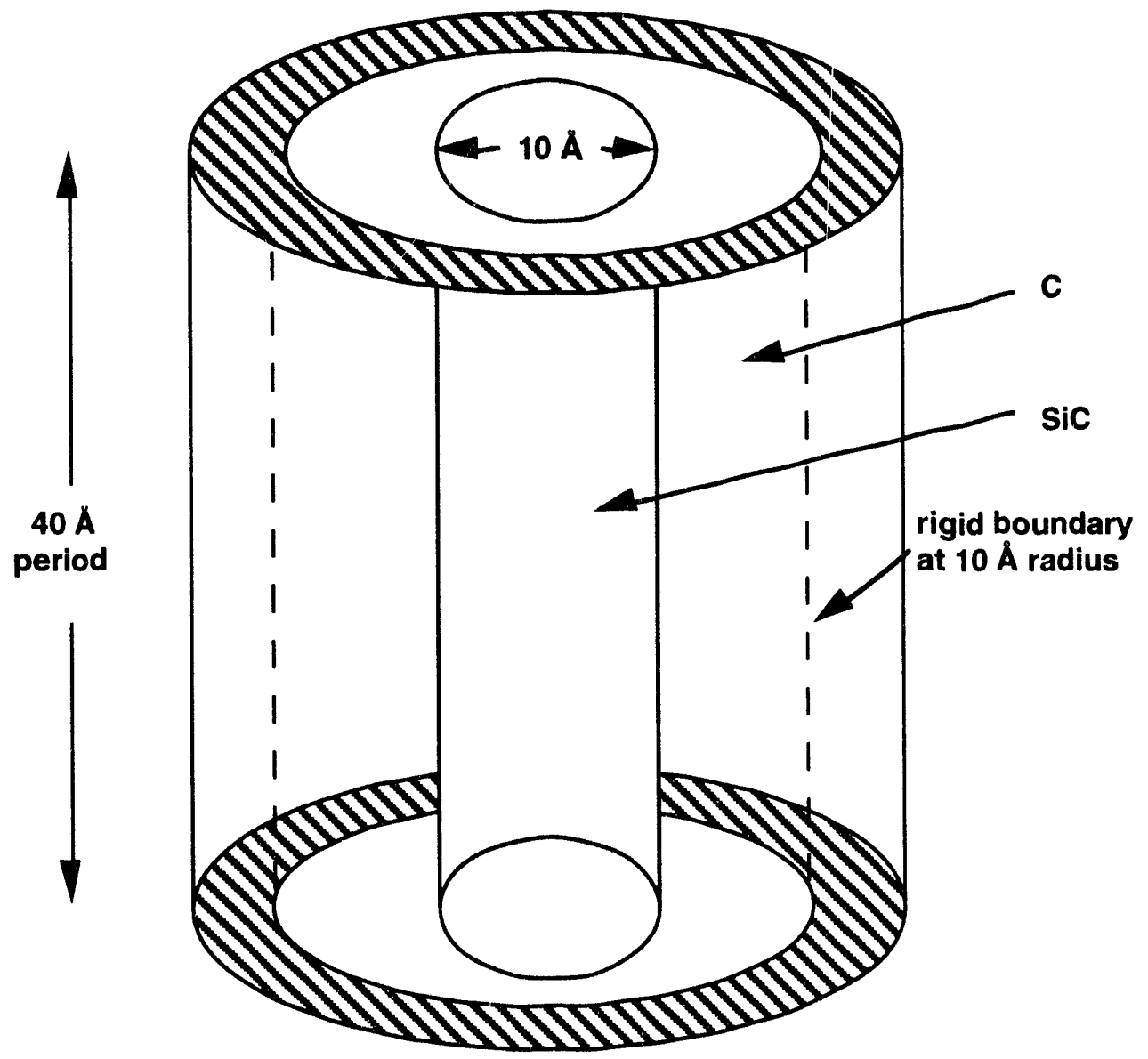

Figure 4 - Geometry of the $\mathrm{SiC}$ fiber in a $\mathrm{C}$ matrix.

In Fig. 5 we see the resulting displacement of the fiber and matrix atoms. The displacement is relatively constant across the fiber and decreases rapidly in the matrix. A significant amount of shear occurs in the fiber near the fiber/matrix interface. If we assume that the applied force, $\mathrm{f}$, acts directly on the matrix, in a continuum model the predicted displacement in the matrix, $\mathrm{d}$, at a radial position, $r$, is given by: 


$$
d=\frac{f^{\prime}(R-r)}{A_{0} C_{44}}
$$

where $R$ is the position of the fixed boundary $(10 \AA)$ and $A_{0}$ is the area $\left(6.32 \AA^{2} /\right.$ atom $)$ that the force acts on. The predicted displacement, as shown in Fig. 5 , is in excellent agreement with the atomistic calculation. At the higher forces the displacement near the interface is somewhat under predicted by the continuum calculation.

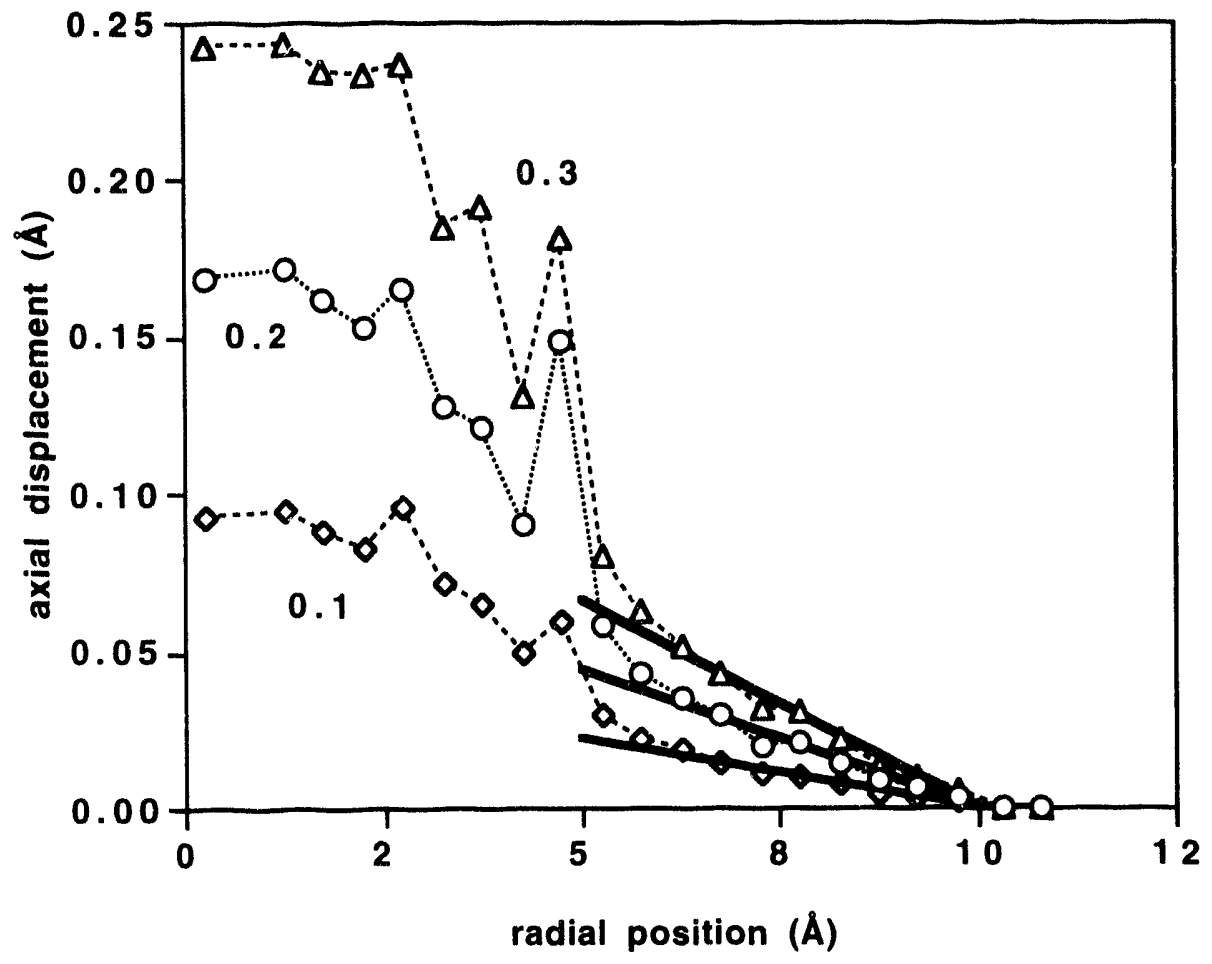

Figure 5 - Axial displacement as a function of radial position. The fiber boundary is at 5 $\AA$. Curves are labeled by the applied axial force (eV/A/atom). The solid lines represent the displacements predicted by a rigid continuum model (Eq. 16).

We have investigated the uniformity of displacement in the fiber and matrix. In a continuum model one would expect a uniform displacement field throughout the length of the computational cell. In the atomistic calculation, however, the $\mathrm{SiC} / \mathrm{C}$ boundary structure varies as we move along the axial direction potentially leading to regions of different adhesion. In essence we have introduced dislocations into the interface to account for the mismatch in the SiC and diamond lattice constants. We clearly see this effect in Fig. $6(a)$. Here we show the axial displacement as a function of axial position for the case of the applied axial force of $0.3 \mathrm{eV} / \AA$ atom. Away from the interface the displacements are relatively uniform as expected from continuum theory. However, the displacements in the SiC fiber near the interface $(r=2.75$ and $4.25 \AA)$ vary by almost a factor of two. A region of large displacements occur near the center of the periodic fiber. The fact that the displacements show a minimum at the boundary of the periodic cell is related to the specific boundary structure. At this axial position the $\mathrm{C}$ and $\mathrm{SiC}$ share a common plane most likely leading to higher adhesion and hence smaller displacements. 
Similarly the SiC/C boundary structure varies circumferentially. In Fig. $6(b)$ we see that the axial displacements do not vary much as a function of circumferential position away from the boundary, but at $r=4.25 \AA$ the displacements are significantly smaller at $90^{\circ}$ and larger at about $300^{\circ}$.

(a)

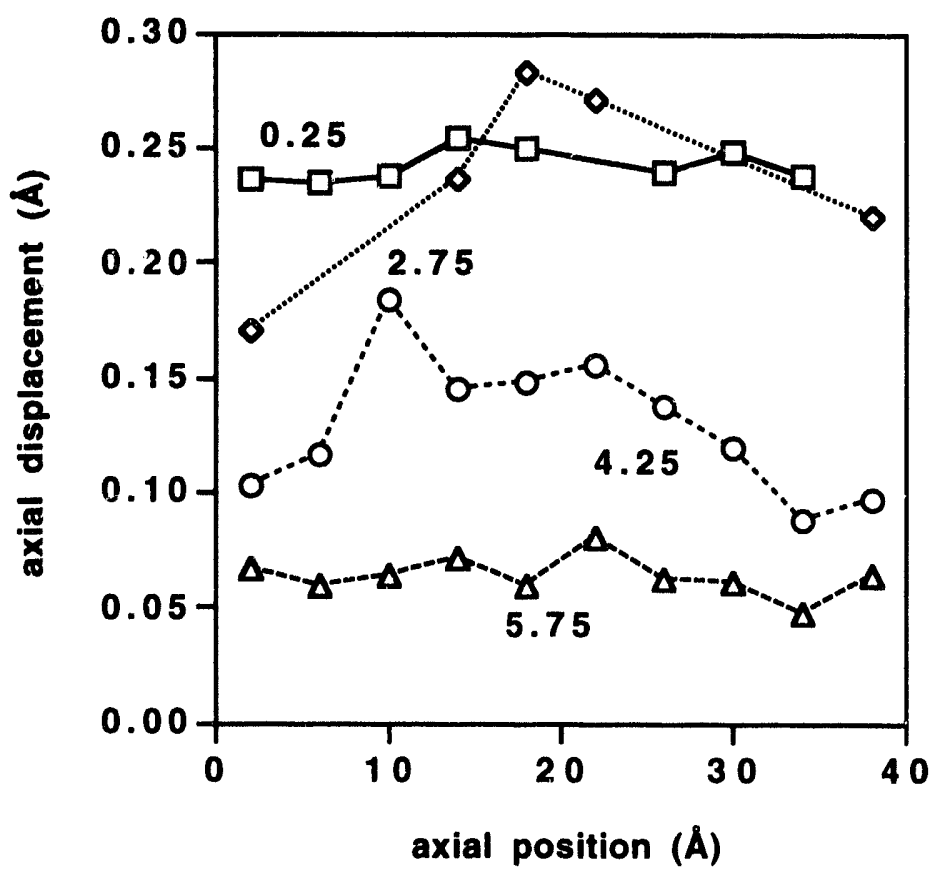

(b)

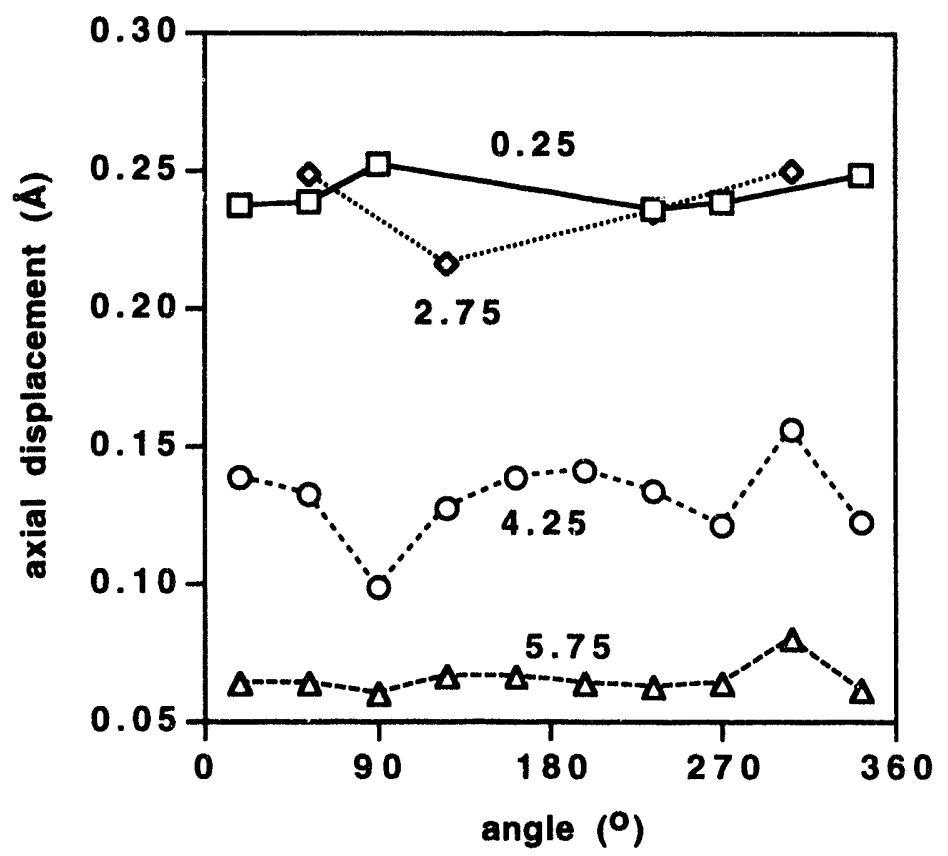

Figure 6 - Axial displacement as a function of (a) axial position and (b) angle for an applied axial force of $0.3 \mathrm{eV} / \AA /$ atom. Curves are labeled by radial position $(\AA)$. The fiber radius is $5 \AA$. 


\section{SUMMARY}

The derivation of the Modified Embedded Atom Method (MEAM) has been presented including a short description of how its parameters are determined. Surface energies and structural energies of a large number of elements are shown to be in good agreement with experiment. Parameters for new MEAM functions for the Si/C system have been determined that fit the properties of $\mathrm{Si}, \mathrm{C}$, and $\mathrm{SiC}$ quite well. Calculations of a $\mathrm{SiC}$ fiber in a diamond matrix show that application of uniform axial forces to the fiber produces non-uniform axial deformation which has been attributed to variation in adhesion at the SiC/C interface. 


\section{REFERENCES}

1. Adams, J. B. and Foiles, S. M., "Development of an Embedded Atom Method Potential for a bcc Metal: Vanadium," Phys. Rev. B, Vol. 41, No. 6, 1990, pp. 3316-3328.

2. Baskes, M. I., "Application of the Embedded-Atom Method to Covalent Materials: A Semiempirical Potential for Silicon," Phys. Rev. Lett., Vol. 59, No. 23, 1987, pp. 26662669.

3. Baskes, M. I., "Modified Embedded-Atom Potentials for Cubic Materials and Impurities," Phys. Rev. B, Vol. 46, No. 5, 1992, pp. 2727-2742.

4. Baskes, M. I., Angelo, J. E., and Bisson, C. L., "Atomistic Calculations of Composite Interfaces," Modelling Simul. Mater. Sci. Eng., Vol. 2, No. 3A, 1994, pp. 505-518.

5. Baskes, M. I., Daw, M. S., and Foiles, S. M., "The Embedded Atom Method: Theory and Application," in Atomic Scale Calculations in Materials Science, Tersoff, J., Vanderbilt, D., and Vitek, V. (eds.), MRS, Boston, MA, 1988, pp. 31.

6. Baskes, M. I., Foiles, S. M., and Daw, M. S., "Application of the Embedded Atom Method to the Fracture of Interfaces," J. de Physique, Vol. C5, 1988, pp. 483-503.

7. Baskes, M. I. and Johnson, R. A., "Modified Embedded Atom Potentials for hcp Metals," Modelling Simul. Mater. Sci. Eng., Vol. 2, No. 1, 1994, pp. 147-163.

8. Baskes, M. I., Nelson, J. S., and Wright, A. F., "Semiempirical Modified Embedded-Atom Potentials for Silicon and Geranium," Phys. Rev. B, Vol. 40, No. 9, 1989, pp. 6085-6100.

9. Bernholc, J., et al., "Mechanism of Self-Diffusion in Diamond," Phys. Rev. Lett., Vol. 61, No. 23, 1988, pp. 2689-2692.

10. Brandes, E. A. (ed.), Smithells Metals Reference Book, 6th ed., Butterworths, London, 1983.

11. Car, R., et al., "Microscopic Theory of Atomic Diffusion Mechanism in Silicon," Phys. Rev. Lett., Vol. 52, No. 20, 1984, pp. 1814-1817.

12. Car, R., et al., "Microscopic Theory of Impurity - Defect Reactions and Impurity Diffusion in Silicon," Phys. Rev. Lett., Vol. 54, No. 4, 1985, pp. 360-363.

13. Carlsson, A. E., Beyond Pair Potentials in Elemental Transition Metals and Semiconductors, Academic Press, Boston, 1990.

14. Daw, M. S., "Embedded Atom Method: Many-Atom Description of Metallic Cohesion," in Atomistic Simulation of Materials, Vitek, V. and Srolovitz, D. (eds.), Plenum Publishing Co., Chicago, 1988, pp. 181.

15. Daw, M. S., "Model of Metallic Cohesion: The Embedded-Atom Method," Phys. Rev. B, Vol. 39, No. 11, 1989, pp. 7441-7452.

16. Daw, M. S. and Baskes, M. I., "Semiempirical, Quantum Mechanical Calculation of Hydrogen Embrittlement in Metals," Phys. Rev. Lett., Vol. 50, No. 17, 1983, pp. 12851288.

17. Daw, M. S. and Foiles, S. M., "Theory of Hydrogen on Metal Surfaces," in First International Conference on the Structure of Surfaces, Van Hove, M. A. and Tong, S. Y. (eds.), Berkeley, CA, 1984, Springer-Verlag, Berlin.

18. Daw, M. S., Foiles, S. M., and Baskes, M. I., "The Embedded Atom Method: A Review of Theory and Applications," Mater. Sci. Rep., Vol. 9, No. 7-8, 1993, pp. 251-310.

19. de Boer, F. R., et al., Cohesion in Metals Transition Metal Alloys, North-Holland, Amsterdam, 1988.

20. Finnis, M. W. and Sinclair, J. E., "A Simple Empirical N-Body Potential for Transition Metals," Phil Mag A, Vol. 50, No. 1, 1984, pp. 45-55.

21. Foiles, S. M., "Calculation of the Surface Segregation of Alloys Using the Embedded Atom Method," in Surface Segregation and Related Phenomena, Dowben, P. A. and Miller, A. (eds.), CRC Press, Boca Rotan, FL, 1990, pp. 79. 
22. Foiles, S. M., Baskes, M. I., and Daw, M. S., "Atomistic Studies of Interfacial Structure and Properties," in Interfacial Structure, Properties and Design, Yoo, M. H., Clark, W. A. T., and Briant, C. L. (eds.), Materials Research Society, Pittsburgh, PA, 1988, pp. 343-365.

23. Foiles, S. M., Baskes, M. I., and Daw, M. S., "The Calculation of the Equilibrium Interface Structure of Alloys," Mat. Sci. Forum, Vol. 37, 1989, pp. 223-234.

24. Foiles, S. M., Baskes, M. I., and Daw, M. S., "Embedded-Atom-Method Functions for the fcc Metals Cu, Ag, Au, Ni, Pd, Pt, and Their Alloys," Phys. Rev. B, Vol. 33, No. 12, 1986, pp. 7983-7991.

25. Hirth, J. P. and Lothe, J., Theory of Dislocations, McGraw-Hill, New York, 1968.

26. Huang, H., et al., "Molecular Dynamics Determination $\beta$-SiC Using Three Representative Empirical Potentials," in preparation.

27. Hyland, B., private communication, 1991.

28. Johnson, R. A. and Oh, D. J., "Analytic Embedded Atom Method Model for bcc Metals," J. Mater. Res., Vol. 4, No. 5, 1989, pp. 1195-1201.

29. Korner, A. and Karnthaler, H. P., "Weak-Beam Study of Glide Dislocations in hcp Cobalt," Phil. Mag. A, Vol. 48, No. 3, 1983, pp. 469-477.

30. Legrand, P. B., "Relations Entre La Structure Electronique et la Facilite de Glissement Dans Les Metaux Hexagonaux Compacts," Phil. Mag. B, Vol. 49, No. 2, 1984, pp. 171184.

31. Partridge, P. G., "The Crystallography and Deformation Modes of Hexagonal Close-Packed Metals," Met. Rev., Vol. 12, 1967, pp. 169.

32. Rose, J. H., et al., "Universal Features of the Equation of State of Metals," Phys. Rev. B, Vol. 29, No. 6, 1984, pp. 2963-2969.

33. Saunders, N., Miodownik, A. P., and Dinsdale, A. T., "Metastable Lattice Stabilities for the Elements," CALPHAD, Vol. 12, No. 4, 1988, pp. 351-374.

34. Savino, E. J., Rao, S., and Pasianot, R., "Beyond the Embedded Atom Interatomic Potential," in Atomic Scale Calculations in Materials Science, Tersoff, J., Vanderbilt, D., and Vitek, V. (eds.), Materials Research Society, Boston, MA, 1988, pp. 43.

35. Tersoff, J., Vanderbilt, D., and Vitek, V. (ed.), Atomic Scale Calculations in Materials Science, 1988, Materials Research Society, Boston, 1988, pp. 471.

36. Tyson, W. R. and Miller, W. A., "Surface Free Energies of Solid Metals: Estimation From Liquid Surface Tension Measurements," Surf. Sci., Vol. 62, 1977, pp. 267-276.

37. Vitek, V. and Srolovitz, D. (ed.), Atomistic Simulation of Materials, Plenum Publishing Co., New York, 1989.

38. Wilks, J. and Wilks, E., Properties and Applications of Diamond, Butterworth-Heinemann Ltd., Stoneham, MA, 1991. 


\section{UNLIMITED RELEASE}

\section{INITIAL DISTRIBUTION}

U. S. Department of Energy

Office of Basic Energy Sciences

Attn: A. L. Dragoo

Washington, D.C. 20545

U. S. Department of Energy

Office of Basic Energy Sciences

Attn: Iran L. Thomas

Washington, D.C. 20545

U. S. Department of Energy

Office of Basic Energy Sciences

Attn: R. Gottschall

Washington, D.C. 20545

Alcoa Technical Center

Alloy Technology Division

Alcoa Laboratories

Attn: Barbara O. Hall

Alcoa Center, PA 15069

AT\&T Bell Laboratories

Attn: M. J. Cardillo

Murray Hill, NJ 07974

AT\&T Bell Laboratories

Attn: Y. C. Chabal

Murray Hill, NJ 07974

AT\&T Bell Laboratories

Attn: M. Grabow

Murray Hill, NJ 07974

AT\&T Bell Laboratories

Attn: D. R. Hamann

Murray Hill, NJ 07974

AT\&T Bell Laboratories

Attn: J. C. Tully

Murray Hill, NJ 07974

Abteilung fur Oberflachenchemie

und Katalys

Universitat Ulm

Attn: R. J. Behm

Albert-Einstein-Allee 11

D-89081 Ulm/Donau

Federal Republic of Germany
Ames Laboratory

Iowa State University

221 Metals Development

Attn: J. H. Rose

Ames, IA 50011

Argonne National Laboratory

9700 S. Cass Avenue

Attn: D. M. Gruen

Argonne, IL 60439

Argonne National Laboratory

Materials Science Division

Bldg. 212

Attn: Dr. Dieter Wolf

9700 S. Cass Avenue

Argonne, IL 60439

Battelle Pacific Northwest

Attn: R. H. Jones

P. O. Box 999

Richland, WA 99352

Brookhaven National Laboratory

Attn: J. W. Davenport

Upton, Long Island, NY 11973

Brookhaven National Laboratory

Attn: K. Lynn

Upton, Long Island, NY 11973

Brookhaven National Laboratory

Attn: D. Welch

Upton, Long Island, NY 11973

Brown University

Department of Physics

Attn: P. J. Estrup

Providence, RI 02912

Dr. R. Bullough

Materials Development Div.

B552 Harwell Laboratory

Oxfordshire OX11 0RA

England

California Inst. of Technology

Attn: T. C. McGill

Pasadena, CA 91125 
California Inst. of Technology

Attn: T. Tombrello

Pasadena, CA 91125

California Inst. of Technology

Attn: W. H. Weinberg

Pasadena, CA 91125

Carnegie-Mellon University

Attn: A. W. Thompson

Dept of Met. Engr. and

Matls. Science

3325 Science Hall

Pittsburgh, PA 15213

Carnegie-Mellon University

Attn: P. Wynblatt

Dept of Met. Engr. and

Matls. Science

3325 Science Hall

Pittsburgh, PA 15213

Cornell University

Laboratory of Atomic and

Solid State Physics

Attn: N. W. Ashcroft

Ithaca, NY 14853-2508

Cornell University

Bard Hall

Attn: J. M. Blakely

Ithaca, NY 14850

Cornell University

School of Chemical Engineering

Attn: Prof. Paulette Clancy

Olin Hall

Ithaca, NY 14853-1501

Cornell University

Dept. of Materials Science

and Engineering

Attn: Prof. S. L. Sass

Ithaca, NY 14853-1501

Eastman Kodak Company

Research Laboratories, Bldg. 81

Attn: Dr. J. R. Lavine

Rochester, NY 14650-2008
EG\&G Idaho, Inc.

Attn: Clinton Van Siclen

Physics Group, MS 2211

P. O. Box 1625

Idaho Falls, ID 83415

Eindhoven University

Attn: H. H. Brongersma

Dept. of Physics

P. O. Box 513

5600 M. B. Eindhoven

The Netherlands

Fritz-Haber Institut

Faradayweg 4-6

Attn: G. Ertl

1000 Berlin 33

Federal Republic of Germany

Fysik Institut

Odense Universitat

Attn: P. Sigmund

DK-5230 Odense M

Denmark

George Washington University

School of Engineering and Applied Science

Attn: Charles Gilmore

Associate Dean for Research

Tompins Hall

Washington, D. C. 20052

Georgia Institute of Technology

Attn: Prof. Uzi Landman

225 North Avenue N.W.

Atlanta, GA 30332

Hahn-Meitner-Institut

Attn: H. Wollenberger

Glienicker Str. 100

1000 Berlin 39, West Germany

Harvard University

Attn: Prof. H. Ehrenreich

Cambridge, MA 02183

Harvard University

Attn: Prof. J. R. Rice

Cambridge, MA 02183 
Haverford College

Department of Physics

Attn: L. Roelofs

Haverford, PA 19041

IBM

Almaden Research

K33.801

Attn: Farid F. Abraham

650 Harry Road

San Jose, CA 95120-6099

IBM

Fishkill Laboratory

Dept. 62G

Attn: Dr. Cheruvu S. Murthy

Hopewell Junction, NY 12533

IBM.

T. J. Watson Research Center

Attn: P. M. Marcus

P. O. Box 218

Yorktown Heights, NY 10598

IBM.

T. J. Watson Research Center

Attn: J. Tersoff

P. O. Box 218

Yorktown Heights, NY 10598

International School for

Advanced Studies

Attn: E. Tosatti

Strada Costiera 11,

Miramare, Trieste 34014

Italy

Institut für Festkörperforschung der Kernforschungsanlage

Attn: P. H. Dederichs

Postfach 1913

D-5170 Jülich 1, West Germany

Institut für Festkörperforschung der Kernforschungsanlage

Attn: H. Ibach

Postfach 1913

D-5170 Jülich 1, West Germany
Institut für Festkörperforschung

der Kernforschungsanlage

Attn: W. Schilling

Postfach 1913

D-5170 Jülich 1, West Germany

Institut für Festkörperforschung

der Kernforschungsanlage

Attn: H. Wenzl

Postfach 1913

D-52405 Jülich, Germany

Institut für Physikalische Chemie

Freie Universität Berlin

Attn: K. Christman

Takush. 3

1000 Berlin 33

Federal Republic of Germany

Institute of Corrosion and Protection of

Metals Academia Sinica

No. 62 Wencui Road

Shenyang 110015

China

Interfaculty Reactor Institute

Attn: Dr. A. van Veen

Mekelweg 15

NL-2629JB, Delft

The Netherlands

International School for Advanced Studies

Attn: V. Bortolani

I-34014 Trieste

Italy

International School for Advanced Studies

Attn: Prof. F. Ercolessi

I-34014 Trieste

Italy

International School for Advanced Studies

Attn: E. Tosatti

I-34014 Trieste

Italy

Iowa State University

Ames Laboratory

Attn: A. E. DePristo

Ames, IA 50011 
Iowa State University

Ames Laboratory

Attn: K.-M. Ho

Ames, IA 50011

Iowa State University

Ames Laboratory

Attn: P. A. Thiel

Ames, IA 50011

Lab. Voor Fysische Metaalkunde

Materials Science Centre

Attn: J. Th. M. De Hosson

Groningen, Nijenborgh 18

The Netherlands

Lawrence Berkeley Laboratory

Materials and Molecular Res. Div.

Attn: M. L. Cohen

Berkeley, CA 94720

Lawrence Berkeley Laboratory

Materials and Molecular Res. Div.

Attn: L. M. Falicov

Berkeley, CA 94720

Lawrence Berkeley Laboratory

Materials and Molecular Res.Div.

Attn: G. A. Somorjai

Berkeley, CA 94720

Lawrence Berkeley Laboratory

Materials and Molecular Res. Div.

Attn: S. G. Louie

Berkeley, CA 94720

Lawrence Berkeley Laboratory

Materials and Molecular Res. Div.

Attn: M. A. van Hove

Berkeley, CA 94720

Los Alamos Natl. Scientific Lab.

P. O. Box 1663

Attn: S. P. Chen

Los Alamos, NM 87545

Los Alamos Natl. Scientific Lab.

Attn: Dr. Terry C. Lowe

MST-5, MS G730

P.O. Box 1663

Los Alamos, NM 87545
Los Alamos Natl. Scientific Lab.

P. O. Box 1663

Attn: D. L. Smith

Los Alamos, NM 87545

Los Alamos Natl. Scientific Lab.

P. O. Box 1663

Attn: A. Voter

Los Alamos, NM 87545

Loyola College

Deparment of Physics

Attn: Prof. R. S. Jones

4501 N. Charles St.

Baltimore, MD 21210

Massachusetts Inst. of Technology

Attn: Prof. A. S. Argon

Cambridge, MA 02139

Massachusetts Inst. of Technology

Attn: Prof. R. M. Latanision

Cambridge, MA 02139

Massachusetts Inst. of Technology

Attn: S. Yip

Cambridge, MA 02139

Max-Planck-Institut für Plasmaphysik

Attn: R. Behrisch

D8046 Garching, West Germany

Max-Planck-Institut für Plasmaphysik

Attn: Professor V. Dose

D-8046 Garching, West Germany

Max-Planck Inst. fur Metallforschung

Inst. fur Werstoffwissenschaften

Attn: M. W. Finnis

Seetrass 92

7000 Stuttgart 1

Germany

Max-Planck-Institut für Metallforschung

Institut für Werkstoffwissenschaften

Attn: Prof. Dr. Phil. H. Fischmeister

Seestrasse 92

7000 Stuttgart 1

Federal Republic of Germany 
Max-Planck-Institut für Metallforschung Institut für Werkstoffwissenschaften

Attn: Dr. W. Mader

Seestrasse 92

7000 Stuttgart 1

Federal Republic of Germany

Max-Planck-Institut für Metallforschung Institut für Werkstoffwissenschaft

Attn: Dr. S. Schmauder

Seestrasse 92

70174 Stuttgart

Federal Republic of Germany

Max-Planck-Institut für

Stromungsforschung

Attn: Prof. J. P. Toennies

Bunsenstrasse 10

D-3400 Göttingen

Federal Republic of Germany

Michigan Technological University

Dept. of Metallurgical Engineering

Attn: J. K. Lee

Houghton, MI 49931

Michigan Technological University

Materials Science Department

Attn: J. R. Waber

Houghton, MI 49931

National Institute of Standards and Technology

Attn: J. M. Rowe, 235/A 106

Washington, DC 20234

National Institute of Standards and Technology

Materials Bldg., Rm. A 113

Attn: R. Thomson

Washington, DC 20234

Naval Research Laboratory

Attn: T. Andreadis, Code 4651

Washington, DC 20375

Naval Research Laboratory

Attn: Michael J. Mehl, Code 4693

4555 Overlook Ave. SW

Washington, DC 20375-5000
Nippon Steel Corporation

Attn: Dr. Tooru Matsumiya

Advanced Materials \& Technology Research

Laboratories

1618 Ida. Nakahara-ku

Kawasaki 211, Japan

North Carolina State University

Attn: J. R. Beeler

Raleigh, NC 27607

Northwestern University

Dept. of Mat. Science \& Engr.

Attn: Dr. David Seidman

2145 Sheridan Road

Evanston, IL 60201-9990

Oak Ridge National Laboratory

Bldg. 4500S, MS 6114

Box 2008

Attn: W. H. Butler

Oak Ridge, TN 37831-6114

Oak Ridge National Laboratory

P. O. Box X

Attn: H. L. Davis

Oak Ridge, TN 37830

Oak Ridge National Laboratory

P. O. Box X

Attn: J. Noonan

Oak Ridge, TN 37830

Oak Ridge National Laboratory

P.O. Box 2008

Attn: D. Pedraza

Oak Ridge, TN 37831-6069

Oak Ridge National Laboratory

P. O. Box X

Attn: J. O. Steigler

Oak Ridge, TN 37830

Oak Ridge National Laboratory

P. O. Box X

Attn: M. Stocks

Oak Ridge, TN 37830

Oak Ridge National Laboratory

Attn: M. H. Yoo

Metals and Ceramics Division

P. O. Box 2008, Bldg. 5500, MS-6376

Oak Ridge, TN 37830 
The Ohio State University

Division of Materials Research

Attn: S. A. Dregia

Columbus, $\mathrm{OH}$ 43210-1106

The Ohio State University

Attn: Prof. P. Shewmon

Dept. Matl. Sci. \& Engr.

116 W. 19th Ave.

Columbus, $\mathrm{OH}$ 43210-1106

The Ohio State University

Physics Department

Attn: J. W. Wilkins

174 West 18th Avenue

Columbus, $\mathrm{OH}$ 43210-1106

Oxford University

Attn: Prof. D. G. Pettifor

Parks Road

Oxford OXI 3PH

England

Oxford University

Dept. of Metallurgy and

Science of Materials

Attn: Adrian Sutton

Parks Road

Oxford OX1 3PH

England

Pennsylvania State University

Attn: Barbara J. Garrison

Department of Chemistry

State College, PA 16801

Queens University

Dept. of Physics

Attn: Prof. Malcolm Stott

Stirling Hall

Kingston, Canada K7L 3N6

Rice University

Attn: Prof. R. B. McLellan

Houston, TX 77251

Rutgers University

Dept. of Ceramics

Attn: Dr. S. H. Garofalini

P. O. Box 909

Piscataway, NJ 08854
Stanford University

Department of Chemistry

Attn: Hans C. Anderson

Stanford, CA 94305

Stanford University

Department of Materials Science \& Engineering

Attn: Timur Halicioglu

Stanford, CA 94305

Stanford University

Dept. of Chemical Engineering

Attn: Prof. R. Madix

Stanford, CA 94305

Stanford University

Department of Chemistry

Attn: Prof. R. Zare

Stanford, CA 94305

Technical University of Denmark

Attn: J. K. Nørskov

Lab. f. Technical Physics

DK-2800 Lyngby, Denmark

Texas A\&M University

Dept. of Nuclear Engineering

Attn: Dr. R. Vijay

College Station, TX 77843

Ukrainian Academy of Sciences

Attn: V. Pokropivny

V. Ogorodnikov

Institute for Problems of Matls. Science

Computer Simulation Laboratory

Ukrainian 252680 KIEV GSP-142

University of Aarhus

Institute of Physics

Attn: F. Besenbacher

DK-8000 Aarhus C, Denmark

University of Aarhus

Institute of Physics

Attn: J. Bottiger

Ivan Stensgaard

DK-8000 Aarhus C, Denmark 
University of California

MANE Department

Attn: N. M. Ghoniem

6275 Boelter Hall

Los Angeles, CA 90024

University of California, Irvine

Department of Physics

Attn: Prof. A. Maradudin

Irvine, CA 92717

University of California, Irvine

Department of Physics

Attn: Prof. M. Mills

Irvine, CA 92717

University of California, Los Angeles

Department of Materials Science and

Engineering

Attn: Royoichi Kikuchi

405 Hilgard Avenue

Los Angeles, CA 90024-1595

University of Connecticut

Center for Materials Simulation

Attn: Professor Phil Clapp

97 North Eagleville Rd.

Storrs, CT 06269-3136

University of Connecticut

Department of Metallurgy

Attn: Jonathan A. Rifkin

97 North Eagleville Rd.

U-136

Storrs, CT 06269-3136

University of Copenhagen

H. C. Ørsted Institute

Attn: H. H. Andersen

Universitetsperken 5

DK-2100 Copenhagen, Denmark

University of Illinois

Dept. of Materials Science

Attn: J. B. Adams

Urbana, IL 61801

University of Illinois

Dept. of Mining and Metallurgy

Attn: H. K. Birnbaum

Urbana, IL 61801
University of Illinois

Nuclear Eng. Lab.

Attn: D. Ruzic

103 S. Goodwin Ave., Rm. 214

Urbana, IL 61801

University of Jyväskylä

Department of Physics

Attn: Prof. R. M. Nieminen

Seminaarinkatu 15

SF - 40100 Jyväskylä

Finland

The University of Liverpool

Dept. of Materials Science and Engineering

Attn: Prof. D. J. Bacon

P. O. Box 147

Liverpool L69 3BX

England

University of Maryland

Department of Physics

Attn: T. Einstein

College Park, MD 20742-4111

University of Maryland

Department of Physics and Astronomy

Attn: Dr. K. E. Khor

College Park, MD 20742-4111

University of Michigan

Dept. of Mat. Sci. and Engr.

Attn: D. Srolovitz

Ann Arbor, MI 48109-2136

University of Michigan

Dept. of Nuclear Engineering

Attn: G. Was

Ann Arbor, MI 48109

University of Minnesota

Dept. of Chemical Engr. and

Materials Science

Attn: J. R. Chelikowsky

151 Amundson Hall

421 Washington Avenue S. E.

Minneapolis, MN 55455 
University of Minnesota

Corrosion Research Center

Attn: W. W. Gerberich

Minneapolis, MN 55455

University of Minnesota

Corrosion Research Center

Attn: R. A. Oriani

Minneapolis, MN 55455

University of New Mexico

Chemistry \& Nuclear Eng. Dept.

Attn: Dr. Anil Prinja

Albuquerque, NM 87131

University of Notre Dame

Dept. Physics

Attn: J. Dow

Box E

Notre Dame, IN 46556

University of Pennsylvania

Department of Materials Science

Attn: V. Vitek

Philadelphia, PA 19104

University of Texas

Depts. of Astronomy \& Physics

RLM 15-212

Attn: R. Smoluchowski

Austin, TX 78712

University of Trieste

Dipartimento di Fisica Teorica

Attn: Prof. N. Parrinello

I-34014 Trieste

Italy

University of Virginia

Department of Materials Science

Attn: R. A. Johnson

School of Engineering and

Applied Science

Charlottesville, VA 22901

University of Wisconsin

ECE Department

Attn: Prof. W. N. G. Hitchon

Madison, WI 53706
Virginia Commonwealth University

Dept. of Physics

Attn: Prof. P. Jena

Richmond, VA 23284-2000

Virginia Commonwealth University Dept. of Physics

Attn: Prof. T. McMullen

Richmond, VA 23284-2000

Washington University

Department of Physics

Campus Box 1105

Attn: Anders Carlsson

St. Louis, MO 63130

Washington State University

Dept. of Mechanical and

Materials Engineering

Attn: Richard Hoagland

Pullman, WA 99164-2920

Westinghouse Savannah River Co.

Attn: Khalid Mansour

Scientific Computation Section

Bldg. 773-42A

Aiken, SC 29802

Westinghouse Savannah River Co.

Attn: Ralph Wolf

Scientific Computation Section

Bldg. 773-42A

Aiken, SC 29802

West Virginia University

Dept. of Physics

Attn: Bernard R. Cooper

Morgantown, WV 26506

A. Gonis, L-268

W. E. King, L-356

E. C. Sowa, L-356

M. J. Weber, L-326

MS 0300 R. L. Schwoebel, 12300

MS 0335 R. J. Eagan, 1100

MS 0337 A. D. Romig, 1800

MS 0343 J. A. Borders, 1823

MS 0344 D. R. Jennison, 1114

MS 0344 G. L. Kellogg, 1114

MS 0345 B. W. Dodson, 1153

MS 0345 D. Emin, 1153

MS 0346 J. E. Schirber, 1002

MS 0349 S. T. Picraux, 1102 
MS 0350

MS 0350

MS 0350

MS 0513

MS 0724

MS 1056

MS 1056

MS 1326

MS 9001 J. C. Crawford, 8000

Attn: D. L. Crawford, 1900

J. B. Wright, 5300

M. E. John, 8100

R. J. Detry, 8200

W. J. McLean, 8300

L. A. Hiles, 8400

P. N. Smith, 8500

L. A. West, 8600

M. T. Dyer, 8800

MS 9006 E. E. Ives, 5200

MS 9011 R. Cline, 1952

MS 9036 W. D. Wilson, 8703

MS 9052 M. Allendorf, 8361

MS 9055 C. M. Rohlfing, 8353

MS 9161 D. C. Chrzan, 8341

MS 9161 S. M. Foiles, 8341

MS 9161 R. B. James, 8341

MS 9161 D. D. Johnson, 8341

MS 9161 G. D. Kubiak, 8342

MS 9161 R. H. Stulen, 8342

MS 9161 W. G. Wolfer, 8341

MS 9163 W. Bauer, 8302

MS 9163 K. L. Wilson, 8304

MS 9214 C. L. Bisson, 8117

MS 9214 C. F. Melius, 8117

MS 9401 C. W. Robinson, 8702

MS 9401 R. C. Wayne, 8700

Attn: J. C. F. Wang, 8713

G. J. Thomas, 8715

J. M. Hruby, 8716

G. A. Benedetti, 8741

P. E. Nielan, 8742

M. L. Callabresi, 8743

R. J. Kee, 8745

W. A. Kawahara, 8746

MS 9402

M. W. Perra, 8714

MS 9402 T. E. Felter, 8715

MS 9402 S. E. Guthrie, 8715

MS 9403 J. E. Costa, 8711

MS 9403 J. E. Angelo, 8712

MS 9403 M. I. Baskes, 8712 (25)

MS 9403 N. R. Moody, 8712

MS 9406
MS 0899 Technical Library Processes

Dept., 7141 (4)

MS 9018 Central Technical Files (3)

MS 9022 Mail Distribution, 8533-1/ Technical Library Processes, 7141

MS 9022 Mail Distribution, 8533-1/ for OSTI (2) 

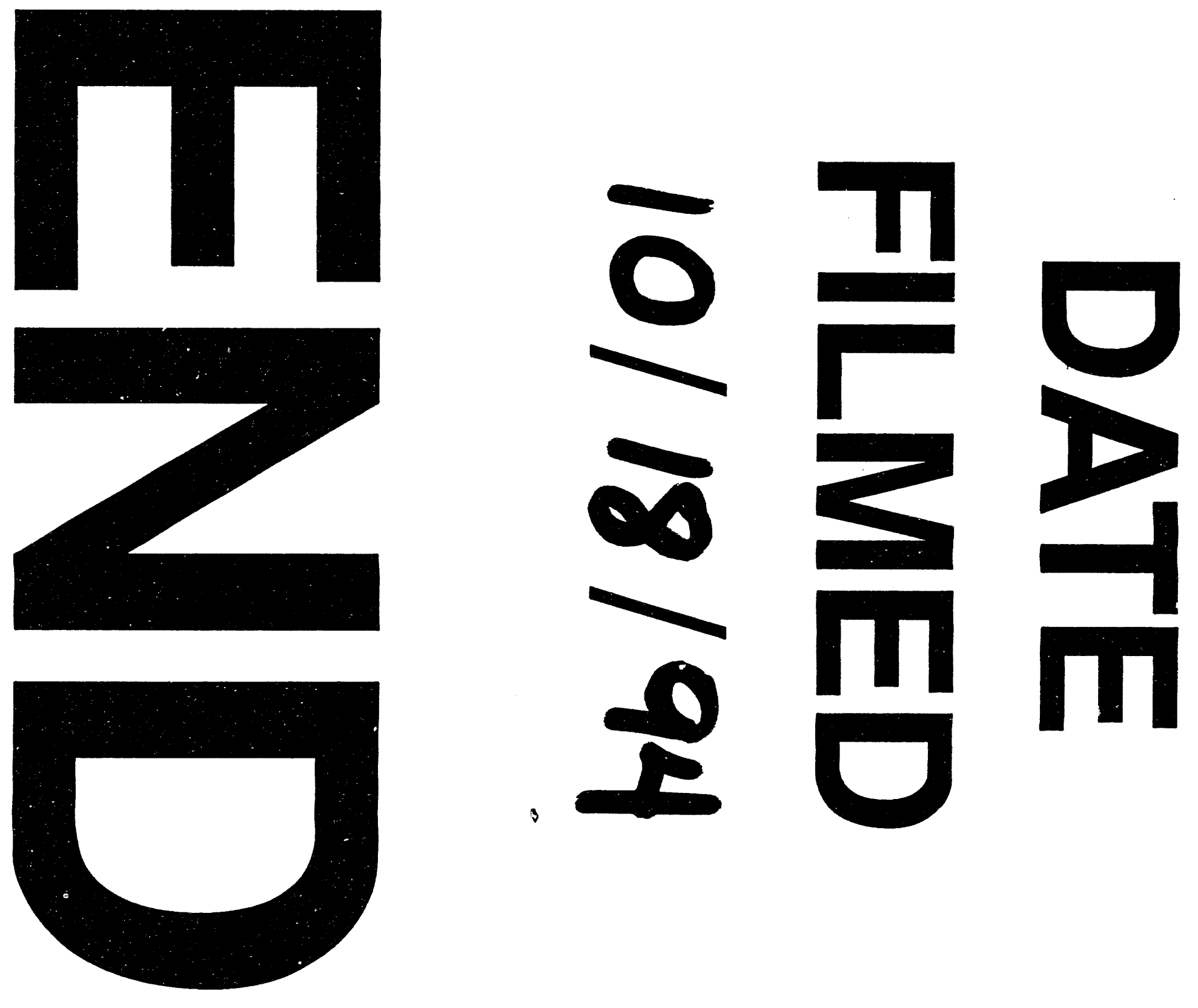